\title{
Positioning Youth Development Agenda in Public Discourse in Nigeria: An Advocacy Imperative
}

\author{
Adebayo Fayoyin \\ Regional Communication Adviser, United Nations Population Fund (UNFPA), Johannesburg, South Africa \\ Email: afayoyin@gmail.com
}

Received 31 August 2015; accepted 16 September 2015; published 23 September 2015

Copyright (C) 2015 by author and OALib.

This work is licensed under the Creative Commons Attribution International License (CC BY). http://creativecommons.org/licenses/by/4.0/

(c) (i) Open Access

\begin{abstract}
Nigeria is currently undergoing what demographers describe as a "youth bulge", which requires significant attention for sound policies in the area of health, education, economy and good governance. Although development agencies have utilised a multitude of tactics to promote youth and children issues in the country, the level of media and public attention is still insufficient. Children and youth advocates confront significant challenges in attracting sustainable public, policy and media attention to the youth development agenda. Thus, the paper advocates for a more effective positioning of youth development in the country through a robust use of big data, appropriate framing of issues, creative networking among advocates to coordinate public influence interventions, and constructive response to counter framing by opposition groups. Advocates also need to be more politically-savvy in navigating the complexities of domestic politics that shape public and policy response to social development while harnessing the power of transnational obligations, norms and institutions in leveraging political support for children and youth.
\end{abstract}

\section{Keywords}

Issue Attention, Advocacy, Public Communication, Framing, Youth

Subject Areas: Journalism and Communication

\section{Introduction}

Nigeria is a demographically diverse country with many issues affecting different population groups: children, adolescents, young people, youth, women, men, older population and key populations. This demographic diversity creates major opportunities and challenges for issue-attention by media, the public and policy makers. However, the focus of this study is on positioning issues that affect the younger population because of their 
demographic significance.

From the 2013 Nigerian Census figures, children and young people constitute over 47 per cent of the 167 million population of the country while at least 100 million Nigerians are less than 30 years [1]. It is projected that the population of young people aged $10-24$ will be 73 million by 2025 and 116 million by 2050. Given that the definition of youth is up to 35 years, the total number of the younger generation in the country is therefore up to 60 per cent of the population. The strategic significance of this population necessitates greater prioritisation of their issues in public discourse.

The Children Act of 2003 identifies major areas of protection for children: prohibition of child marriage, child betrothal, infliction of skin marks, abduction, forced, exploitative, and hazardous child labour, child hawking, begging for alms, prostitution, unlawful sexual intercourse and other forms of sexual abuse and exploitation prejudicial to their welfare [2]. Moreover, the country is expected to change its policy and legal instruments progressively in line with international standards and obligations, but beyond the policies to be formulated, advocates also face the challenge of policy implementation.

The national youth development situation analysis observes that young people are key actors and a driving force for national development but if mismanaged, Nigeria's burgeoning youth population could have catastrophic future consequences. This population is affected by a multiplicity of problems that need significant public and policy attention. At least 40 percent of the population of young people aged 15 - 25 are jobless [3] while according to the National HIV and AIDS Reproductive Health survey sexual and reproductive health, including HIV deserve more attention [3]. HIV prevalence between 15 - 19 years and 20 - 24 years are 2.9 per cent and 3.2 per cent respectively. Various segments of the population group are exposed to risky sexual behaviour such as engaging in multiple and concurrent relationship, low risk perception and inconsistent condom use. Furthermore, at least 47 per cent of young people need various forms of protection measures.

Like most African countries, Nigeria's youthful population needs considerable investment for the transformation of the country [4]. Achieving this requires enhanced strategic portrayal of such issues in national and public discourse for appropriate policy response [3]-[5]. However, the optimal development of these groups is negatively constrained by different systemic and programmatic challenges which call to question the effectiveness of media and communication approaches implemented to amplify their issues at national and community levels. It also underscores why advocacy matters in positioning youth agenda in the country.

\section{Public Attention to Youth Issues}

There is overwhelming evidence that the level of attention to issues affecting the younger generation is wavering and insufficient. From an analysis of 600 stories covering a five-year period coinciding with the passage of the Children's Act, Oyero [5] found that there were only 193 stories published on children by two main newspapers, Daily Times and The Guardian. The study demonstrated that child rights issues were not given any significant attention by the media, and this led to the conclusion that children and young people are 'invisible and voiceless' in Nigerian news media. The finding is consistent with those of [6] who observed that the mass media have not been effective in advancing human rights in Nigeria. While noting that the characterisation of children is largely patronising, the authors argue that the mass media should be massively employed to wage war against gender discrimination and violence against women and children. The paper also recommends greater participation of children and young people in public mobilisation and campaigns to address the problems of child labour and school dropout.

Moreover, findings [7]-[9] have underscored the inadequate attention of the mass media to children and young people in Nigeria. From their analysis, they advocated for intense engagement of the media in covering activities relating to the survival, development and protection of children and young people.

Media reportage of public health issues that largely affect young people and youth also follows a similar wavering cycle of attention. For example, a content analysis by Population Council [9] of sexual and reproductive health, HIV and AIDS as they affect adolescent and youth people demonstrated a huge gap in the coverage. Of the 746 stories published by six newspapers in 2012, only 50 of the stories focussed on adolescent and young people. In addition, the stories were considered as conservative in their approach to sexuality issues and were not bold enough in advocating the right of adolescent and young people in taking charge of their sexuality. Overall, the study lamented the poor level and quality of reportage of sexual and reproductive health and HIV issues as they affect adolescents and young people. However, another study [10] argues that reporting on HIV in 
the country, especially focussing on young people, has improved. In a follow up to a pilot study, the author found that from 2006-2006; there was significant progress in reporting of HIV/AIDS.

In the same vein, an assessment by Journalists against AIDS of the coverage of HIV indicated improvement in the quantity and quality media coverage of HIV issues in the country. However, all the studies agree on the need to sustain media coverage of HIV and sexual and reproductive health in the country through accurate press reporting, enhanced collaboration with media institutions and more targeted information dissemination.

Another interesting strand on the narrative is the image and portrayal of young people in media and social discourse. It is argued that media portrayal of youth and young people tends to reinforce the stereotypes of youth as a problem to be solved rather than a resource to be harnessed. In a study on youth violence in Nigeria's Fourth Republic, [11] submits that young people are largely associated with violence, murder, robbery, rape, riot cultism and ethno-religious violence which has serious political and development ramifications. According to the author, the mass media is a major contributor to the upsurge of the phenomenon through the importation of violent films on television and the brutalities aired an assertion which is difficult to prove.

Examining the representation of youth in some popular Nollywood films [12] concluded that the pattern of portrayal reinforces the stigma of youth as "hate figures" to be despised and scorned by the viewers. The dominant male characters in the stories are depicted as "skirt-chasing, hormone bound, irreverent and dishonest," an image that is capable of stigmatising them and inciting the disavowal of the viewer (p. 174). They argue that even at the resolution of the stories, young people are still stereotyped as not to be trusted, scornful of adult values and should be consigned to "rogues gallery". While there may be other media packages that portray youth in a different light, this study reflects extensively on the literature that profiles youth as problems and dangerous trouble makers.

Finally, in order to generate "real time" perspectives from young people on the topic, the author undertook an exploratory research as part of the process of writing this paper. Key informants interviews were undertaken with Nigerian members of the Africa Youth and Adolescent Network for Population and Development (AFriYAN) on their perception on the kind of attention they get in media, public and policy domains. Preliminary findings suggest that young people perceive the attention from media and public domains as both inadequate and worrisome. One informant said: "You get more stories of rape, unemployment and many degrading issues, and annoyingly it ends there. Nothing more" [13]. Another young person said: "It feels like the media are dismissive of youth issues. Young people hit the headlines when negative things happen. It also feels like the public does not care much about its live-wire-children and youth.” [14]. These observations align with earlier articulation that youth do not receive optimal attention in the media and public discourse to inform policy agenda.

From the foregoing, we submit that despite the myriad of communication and mobilisation efforts to position children and youth issues in Nigeria, the level of media and public attention is fragmentary and inadequate. In general, this important demographic is romanticised as 'leaders of tomorrow' [12] [13] while experiencing many disempowering situations and conditions today [2]-[4]. Millions of our youthful population are victims of violence, abuse and other forms of exploitation that undermine their holistic development. This calls to question the level of prominence that such important issues attract in the society and the effectiveness of the public communication approaches implemented to amplify their issues in public discourse.

The demographic significance of this population in Nigeria's transformative agenda is evident; yet, our study clearly shows that the level and quality of attention in media, public and policy domains is not commensurate. This necessitates the need for more action to ensure that their issues are effectively positioned in public arenas.

Based on the following, this paper proposes a strategic and effective advocacy agenda to enhance the level of media and public attention to issues affecting young people in the country.

\section{Recommendations}

\subsection{Use of Data and Evidence}

The use of research and strategic information has been recognized as an important element of in attracting attention to social issues [15]-[17]. Thus for positioning children and youth issues for a higher level of social, policy and political action, a much stronger emphasis on the use of evidence, research and big datais indispensable. This is part of the larger discussion on the role of role of big data in contemporary decision making and public affairs. Expounding on the value of big data, [18] posit that data is no longer regarded as static or stale but now a major raw material in business and a vital tool for creating new economic value. They argue that big data is 
poised to shake up everything in life from business to the science of healthcare, government, education, economics, the humanities and every aspect of the society. Moreover, big data is now seen as an important resource which needs to be mined and effectively utilized for social change. Scaling up the use of strategic information through big data is essential in promoting population and public health issues. The existence and use of big data in development is consistent with data journalism which focuses on letting numbers tell stories. With the existence of massive data on various children and youth issues, we argue that media reporting on such issues could also be enhanced. Nevertheless, the use of big data has its limitations in decision making on various levels, especially in the areas of political influence, policy change and cultural transformation. These are complex areas of the society which are profoundly difficult to be determined by big data algorithms and predictive modelling approaches. To a large extent, policy change defies the linear Newtonian impulse of “data in decision out” while cultural change cannot be converted to binary probability calculations. Despite the obvious limitations of datadriven decision making noted above, the big data era presents fundamental opportunities for advocacy and for advocates.

\subsection{Compelling Story Telling}

While data is crucial in social influence, hard and cold statistics do not have an impact on the heart without creative communication [19] [20]. Specifically, it has been argued that human beings are not moved to action by data dumps, complicated power point slides or spreadsheets packed with figures [21]. The emotional impact of story-telling in communication has caused many agencies to start converting data into stories through various forms of visualization software and compelling human interest stories to connect with emotion of decision makers. Thus, the combination of the force of ideas and creative story telling (targeting the head and the heart) will go a long way in positioning children and youth issues with different audience groups.

\subsection{Comprehensive Mapping of Issues}

Issues affecting the youthful population are vast and complicated. This is why any attempt to position them must start with a comprehensive mapping of their multidimensional scope and ramification. They must also be grounded on core human rights principles and the life-cycle approach. Our analysis has demonstrated that we need a coherent narrative which is sensitive to the various transitions that take place from childhood to adulthood. From this point of view, we propose the following spectrum of issues that advocates need to address for holistic development of this population. Integral to the areas outlined above is a myriad of specific programme, policy, and service that require the action of specific decision makers. Therefore, a detailed understanding of the issues based on insights from public health and development programming is helpful in building a narrative that enhances effective positioning of the issues that affect the population in question.

\subsection{Creative Issue Framing}

Linked to issue mapping is effective framing through adequate use of language and creative packaging. Framing helps to heighten the level of emotional connection to social issues [22]-[24] While field experience has demonstrated that social issues sketched above are not quite as "juicy" or "sexy” as political or business issues, we propose deeper knowledge of the issues and more creative communication to improve how the issues are promoted and positioned. Also, children and youth advocates will need to integrate targeted messaging that respond to the ecological dimensions on the levels of influence required. In addition, our courses in health communication, media advocacy and public communication need to prioritise participatory modes of communication which strengthen multiple conversations around these issues. We need to move away from linear mode of communication to interdependent conversations around these issues. Advocates need to maximise the pervasiveness of the digital media and the democratization of new media technologies for compelling issue framing and positioning.

How it is necessary to note that children and youth issues have the potential of being embroiled in opposition campaign and controversy, thus advocates need to be mindful of how to manage adversarial advocacy and counter movements. From a conceptual viewpoint, opposition advocacy is not new, as the environmental context for advocacy and social change is replete with counter movements and counter constructions to social issues. In fact, one could argue that but for the existence of opposition and resistance, there might not be the need to carry out advocacy. Opposition even comes from the least expected quarters such as experts and intellectuals, either 
due to intellectual disagreement or divergent views of science. Opposition might be based on the personal preferences of the decision maker or the need to be politically correct. The source of resistance to issues may also be rooted in intellectual, ideological, religious, political, personal or philosophical differences.

For example, children rights have been a major source of debates and opposition in Nigeria. Specifically, during the process of reforming the child rights laws in the country, one of the sticky points was the "compatibility” of international child rights norms with traditional cultural and practices on child. Also, providing comprehensive sexuality education has been embroiled in twisted public debates which sometime equate this with sex education and the distribution of condoms in schools. Even relatively straightforward interventions and programmes like prevention or elimination of mother to child transmission of HIV, exclusive breastfeeding and polio immunization have seen quantum opposition and resistance for different reasons.

Moreover, coordinated anti-vaccination campaigns in Nigeria have had significant effects on the impact of the polio programme in the country [25] [26]. This was based on rumors that the vaccines were laced with anti- fertility drugs intended to reduce the population of northern Nigeria [27]. The controversy led to the abandonment of polio immunization in 2003 and 2008 in the northern part of the country. Thus, in addressing resistance, advocates need a good analysis of opposition position and its changing pattern. This is because opposition to social issues is never static, but ever changing. In some cases, it rebrands itself and adopts the arguments of mainline advocates. Such a situation also requires the use of sophisticated arguments and multiple discourses to mitigate the impact of opposition. Ultimately, youth and children advocates need to prioritise how to ameliorate counter frames and non-supportive constructions of their issues.

\subsection{Building Advocacy Coalitions}

Influencing the media, public and policy agenda platforms is a complex task. It involves the engagement of different actors and stakeholders with sometimes complimentary or competitive intentions. This is why strategic networking is an indispensable element of the role of children and youth advocates. Network approaches assume that the contemporary policy making process is influenced by different actors such as government institutions (executive, legislature, judiciary), political parties, supra national governmental and non-governmental institutions, the mass media, and policy communities [28] [29]. Other actors are private sector institutions (with different raison deter), public sector organizations and non-state actors. Thus, positioning children and youth issues in media, public and policy domains requires interdependence of actions and advocates need to continue to invest in strategic engagement which would help to mobilise necessary allies, coalitions, and groupings.

\subsection{Navigating Local Political Context}

Politics plays a major role in how issues receive attention in any society; therefore advocates need to be politically savvy in their efforts at positioning children and youth issues in public discourse. In an editorial entitled Good Politics, Bad Politics: The Experience of AIDS, [30] traced the connection between politics and science in achieving public health outcomes. They argue that building on the history of political action around health issues, "engagement of political leadership at all levels is, without doubt, essential to effectively addressing significant public health issues” (p.1936). Thus, issue positioning requires a high level of political negotiation. Essential skills to assist in this process are social influence, diplomacy and political communication. Also, effectively navigating the policy and political dimensions of issue positioning entails deployment of reason and multiple forms of argumentation.

\subsection{Leveraging Transnational Influence}

Social issues have international and global dimensions. Children and youth issues are now framed by international human rights norms and treaties, which require international obligations. We therefore argue that children and youth advocates need to continuously use international instruments, agencies, actors and platforms to help in positioning such issues in policy and media discourse. This is in line with findings from [15] [31] which established that transnational influence and networks in achieving social change. Nigeria is a signatory to many instruments that relate to children and youth issues, such as CRC, CEDAW, and Africa Charter on Children Rights. These instruments and their reporting obligations could be leveraged to highlight children and youths in the country. 


\section{Conclusion}

A UNICEF report, Generation 2030 Africa points to the need to place special attention on Nigeria's youthful population [32]. It adds that by 2015 about one fifth of the continents birth will be taking place in the country alone while from 2015-2030 at least 136 million births are expected. Other demographics to focus on are adolescents, especially girls. Besides, the plight of youth in terms of employability and economic empowerment begs for significant attention. Overall, addressing the challenge of the youthful population is fundamental to Nigeria's development. This is why the strategic positioning of their issues can no longer be secondary in our public and health communication interventions. Our analysis has shown that several public communication approaches have been implemented by development agencies and their partners in influencing media, public and policy domains. However, evidence suggests that the level of attention is inadequate and incoherent. The study makes some recommendations to stimulate more attention for children and youth issues in the country. Specifically, advocates need to integrate the power of ideas with appropriate framing, meaningful public participation with aggressive mitigation of adversarial campaign, and maximizing the importance of coalition of supporters with transnational influence. The coordinated implementation of these recommendations should enable children and youth advocates to get substantial traction for issues affecting the younger generation in the country.

\section{References}

[1] NPC (2013) Nigeria Demographic and Health Survey. Abuja.

[2] UNICEF (2010) Situation Analysis of Children and Women in Nigeria. UNICEF, Abuja.

[3] UNFPA/PRB (2012) Status Report: Adolescents and Young People in Sub-Saharan Africa-Opportunities and Challenges. UNPFA/PRB, Johannesburg/Washington.

[4] UNFPA (2013) Report on Media Advocacy Workshop in the International Conference on Population and Development, (ICPD), Johannesburg, South Africa, 18-21 August 2013.

[5] Oyero, O. (2010) Children: As "Invisible" and Voiceless as Ever in the Nigerian News Media. Estudos em Communicacao, 2, 25-41.

[6] Asemah, E.S., Edegoh, L.O. and Ogwo, C (2013) Employing the Mass Media for the Promotion of Human Rights in Nigeria. Africa Research Review, 7, 47-60. http://dx.doi.org/10.4314/afrrev.v7i1.4

[7] Nwodu, L.C. and Ezeoke, C.B. (2013) An Evaluation of Press Coverage of Children and Women’s Rights in Nigeria. Higher Education of Social Sciences, 42, 41-51.

[8] Awosika, R.K. and Omoera, O.S. (2008) Child Rights and the Media: The Nigerian Experience. Studies in Home \& Community Science, 2, 125-131.

[9] Population Council (2012) Baseline Survey of Nigerian Media Coverage of Youth Sexual and Reproductive Health and HIV and AIDS Related Issues, Jan $1^{\text {st }}-31^{\text {st }}$, Abuja, Nigeria.

[10] Komolafe-Opadeji, H.O. (2008) Promoting Public Awareness of HIV/AIDS in Africa. Follow-Up to a Pilot Study. Library Philosophy Practice. (Online) http://www.webpages.uidaho.edu/-mbolin/komolafe.htm

[11] Muhammed, A.Y. (2005) Youth Violence in Nigeria’s Fourth Republic: Implications for Uman Development in the 21st Century. Journal of Political Science Review, 4, 1-15.

[12] Ekwenchi, O., Adum, A.N. and Uzuegbunam, C.E. (2013) Youth, Popular Discourse and Power: A Critical Analysis of Three Nollywood Feature Films. Covenant Journal of Communication, 1, 163-180.

[13] Oliko, K. (2014) Personal Communication, 17 July.

[14] Orowe, E. (2014) Personal Communication, 20 August.

[15] Shiffman, J. (2009) A Social Explanation for the Rise and Fall of Global Health Issues. Bulletin of the World Health Organization, 87, 608-613. http://dx.doi.org/10.2471/BLT.08.060749

[16] Shiffman, J. (2007) Generating Political Priority for Maternal Health Reduction in 5 Developing Countries. American Journal of Public Health, 97, 796-803. http://dx.doi.org/10.2105/AJPH.2006.095455

[17] Fayoyin, A. and Ngwainmbi, E. (2014) Use and Misuse of Data in Advocacy, Media, and Opinion Polls: Challenges, Realities and Opportunities. Journal of Development and Communication, 3, 528-545.

[18] Mayer-Schonberger, V. and Cukier, K. (2013) Big Data. Mariner Books, Boston.

[19] Ayres, I. (2007) Super Crunchers. Bantam Books, New York.

[20] Fayoyin, A. (2013) Advocacy as a Strategy for Social Change: A Qualitative Analysis of the Perceptions of UN and Non-UN Development Workers. Journal of Social Studies, 35, 181-193. 
[21] Heath, C. and Heath, D. (2008) Made to Sick: Why Some Ideas Take Hold and Other Come Unstuck. Arrow Books, London.

[22] Entman, R.M. (1993) Framing: Toward Clarification of a Fractured Paradigm. Journalism of Communication, 43, 5158. http://dx.doi.org/10.1111/j.1460-2466.1993.tb01304.x

[23] Weaver, D.H. (2007) Thoughts on Agenda Setting, Framing and Priming. Journal of Communication, 57, $142-147$. http://dx.doi.org/10.1111/j.1460-2466.2006.00333.x

[24] Scheufele, D.A. and Tewksbury, D. (2007) Framing, Agenda Setting and Priming: The Evolution of Three Media Effects Models. Journal of Communication, 57, 9-20.

[25] Fayoyin, A. (2014) Controversies in Public Health: A Case for Prioritizing Integrated Communication in Public Health Interventions in Africa. In: Ngwainmbi, E., Ed., Healthcare Management Strategy, Communication and Development Challenges and Solutions in Developing Countries, Lexington Books, New York, 187-208.

[26] IMB (2013) International Monitoring Board Global Polio Programme Eradication Initiative. Seventh Report, May 2013.

[27] Chen, C. (2004) Rebellion against Polio Vaccine in Nigeria: Implications for Humanitarian Policy. African Health Sciences, 4, 205-207.

[28] Sabatier, P.A. and Weible, C.M. (2007) The Advocacy Coalition Framework: Innovations and Clarifications. In: Sabatier, P.A., Ed., Theories of the Policy Process, West Press, Colorado, 189-220.

[29] Adam, S. and Kriesi, H. (2007) The Network Approach. In: Sabatier, P.A., Ed., Theories of the Policy Process, West Press, Colorado, 129-154.

[30] Piot, P., Russel, S. and Larson, H. (2007) Good Politics, Bad Politics: The Experience of AIDS. American Journal of Public Health, 97, 1934-1936. http://dx.doi.org/10.2105/AJPH.2007.121418

[31] Keck, M.E. and Sikkink, K. (1998) Activists beyond Borders: Advocacy Networks in International Politics. Cornell University Press, Ithaca.

[32] UNICEF (2014) Generation 2030/Africa. UNICEF, New York. 